\title{
Direct Synthesis of Graphene on Silicon at Low Temperature for Schottky Junction Solar Cells
}

\author{
Sudip Adhikari ${ }^{1,2}$, Rucheng Zhuㅜㄹ, Masayoshi Umeno ${ }^{1}$ \\ ${ }^{1}$ C's Techno Inc., Co-Operative Research Center for Advanced Technology, Nagoya Science Park, Nagoya, Japan \\ ${ }^{2}$ Engineering Department, Chubu University, Kasugai, Japan \\ Email: sudip@isc.chubu.ac.jp
}

How to cite this paper: Adhikari, S., Zhu, R. and Umeno, M. (2021) Direct Synthesis of Graphene on Silicon at Low Temperature for Schottky Junction Solar Cells. Journal of Materials Science and Chemical Engineering, 9, 1-9.

https://doi.org/10.4236/msce.2021.910001

Received: August 30, 2021

Accepted: October 23, 2021

Published: October 26, 2021

Copyright $\odot 2021$ by author(s) and Scientific Research Publishing Inc. This work is licensed under the Creative Commons Attribution International License (CC BY 4.0).

http://creativecommons.org/licenses/by/4.0/

\begin{abstract}
Graphene thin films synthesized directly at low temperature $\left(550^{\circ} \mathrm{C}\right)$ on silicon substrate by microwave (MW) surface wave plasma (SWP) chemical vapor deposition (CVD) using the cover on substrates for avoiding plasma emission ultraviolet ray's effect during film deposition. Analytical methods such as Raman spectroscopy, Transmission electron microscopy (TEM) and Scanning electron microscopy (SEM), four-point probe method, and JASCO V-570 UV/VIS/NIR spectrophotometer were employed to characterize the properties of the graphene films. Here, we report that it is possible to grow graphene directly on the silicon substrate (without using catalyst) due to the high radical density of MW SWP CVD. Furthermore, we fabricated graphene/ silicon Schottky junction solar cells with an efficiency of up to $6.39 \%$. Compared to conventional silicon solar cells, the fabrication process is greatly simplified; just graphene is synthesized directly on n-type crystalline Si substrate at low temperate.
\end{abstract}

\section{Keywords}

Graphene, Direct Synthesis, Microwave Plasma CVD, Photovoltaics

\section{Introduction}

Graphene is a single layer of carbon that has a hexagonal (honeycomb) lattice with a carbon-carbon distance of $0.142 \mathrm{~nm}$. It is the first two-dimensional crystalline material and represents whole $2 \mathrm{D}$ material. Since the discovery of mono and few layers of graphene film (2004), it has become an attractive research topic in nanomaterial society due to its many unique properties such as physical, chemical, electrical, mechanical, thermal, conductive, and possible use of low-cost transparent electrodes, touch screen panel, photovoltaic solar cells and 
microelectronic devices [1]-[12].

However, obtaining the quality of graphene films by low-cost deposition method is a still significant challenge, a single process of graphene synthesis at low temperature is highly desirable. In fact, researchers are concentrated to do research on the different methods of graphene synthesis in recent years [8] [10] [11]. Several methods have been explored to prepare graphene on various substrates, like, thermal CVD, micromechanical cleavage or chemical exfoliation of graphite, thermal decomposition of $\mathrm{SiC}$ on copper and nickel substrates [12] [13] [14]. Among various methods, thermal CVD has been a main popular method to synthesize graphene everywhere, however, it requires high temperature (above $\sim 1000^{\circ} \mathrm{C}$ ), catalyst films, post-transfer, and additional catalyst removal process are needed. For leaving this complicated graphene synthesis process, direct growth of graphene without using any other catalyst is very attractive.

In this work, we synthesized graphene directly (without using catalyst) on silicon substrate by MW-SWP CVD using the hydrocarbon as a source gas at low temperature $\left(550^{\circ} \mathrm{C}\right)$. We believed that the direct synthesis of graphene on silicon is possible due to the high radical density of MW-SWP CVD. MW-SWP CVD is a promising plasma source among the various types of existing plasma sources for the deposition of graphene thin film [15] [16]. For making the highquality graphene, we used the cover on substrate for avoiding plasma emission ultraviolet ray's effect; ultraviolet rays could increase defect density of graphene films. In addition, we fabricated graphene/silicon (Gi/Si) Schottky junction solar cells and characterized their photovoltaics properties. Figure 1 shows a schematic of the Gi/Si Schottky junction solar cells development process steps.

\section{Experimental Details}

Graphene film synthesized by MW-SWP CVD on silicon substrate. Figure 2

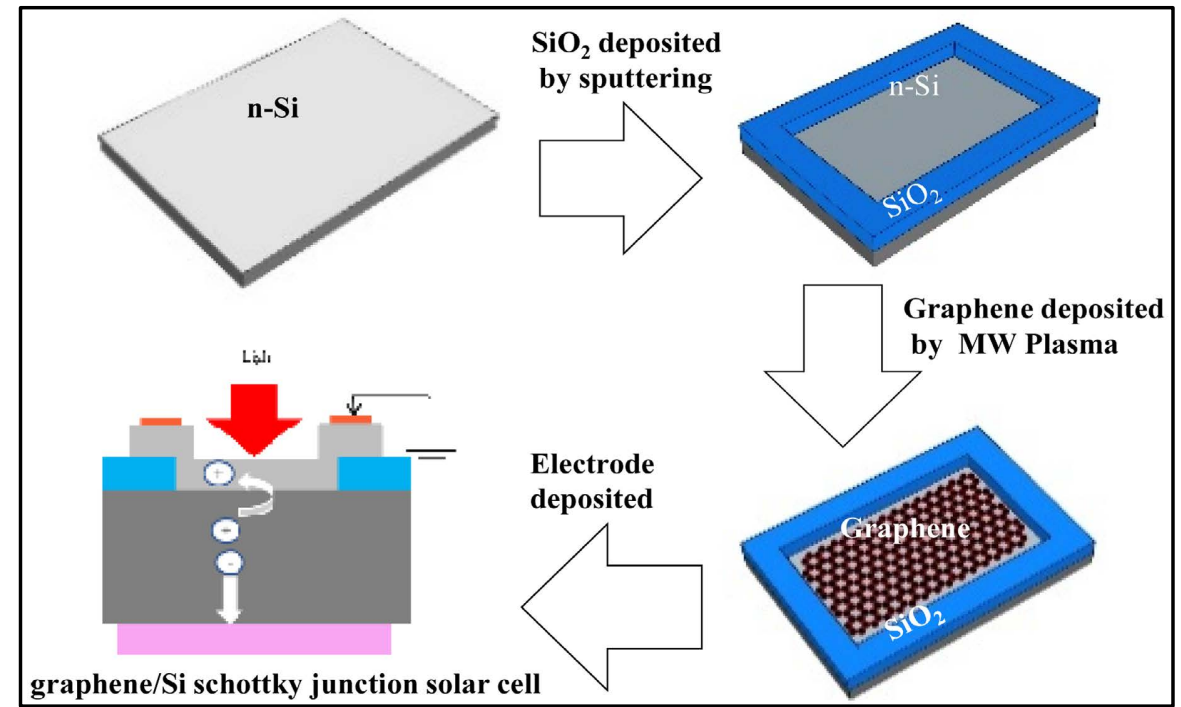

Figure 1. Schematic of the graphene/silicon Schottky junction solar cells development process steps. 


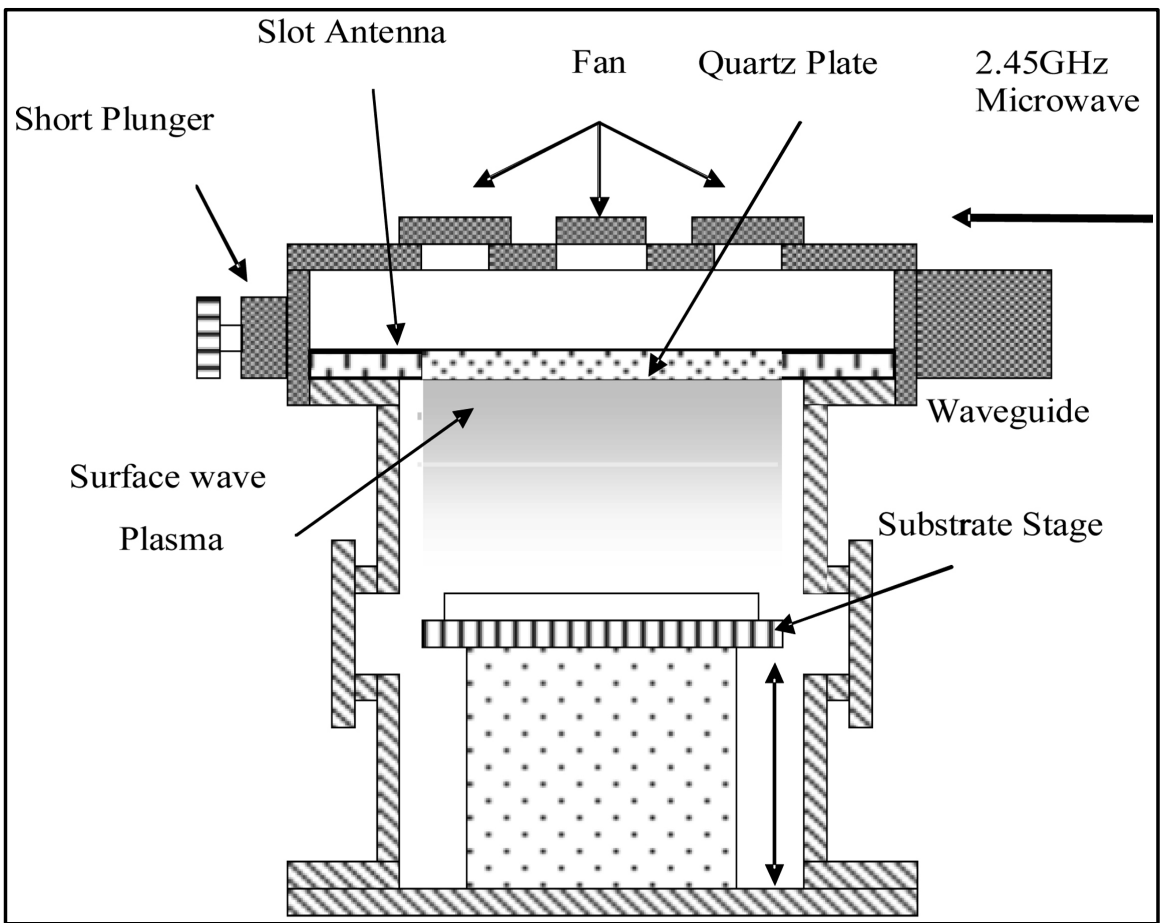

Figure 2. Schematic diagram of MW-SWP CVD.

shows schematic diagram of the MW-SWP CVD system. In this system, MW power, gas flow rate and deposition time-duration are controlled by touchscreen computer system. Due to the large stage diameter $(20 \mathrm{~cm})$ of the CVD, it is possible to deposit a relatively large area of graphene thin film or make simultaneous film deposition on various substrates in one experiment. The maximum MW power of the CVD system is $3 \mathrm{~kW}$, whereas the stage temperature can be controlled up to $800^{\circ} \mathrm{C}$. The MW-SWP is produced in a $300 \mathrm{~mm}$ cylindrical vacuum chamber by introducing a $2.45 \mathrm{GHz} \mathrm{MW}$ through a quartz window via slot antennae. The MW introduced through the slot antennae drops exponentially below the quartz window where the electron density exceeds the cut-off density. A high plasma density with a uniform electron density of more than $10^{11}$ $\mathrm{cm}^{-3}$ is formed in the vacuum chamber and broadened in the downstream region due to particles diffusion [15]. Unlike other plasma sources, the SWP is a promising plasma source for large-area thin film deposition.

Argon (Ar: $100 \mathrm{sccm})$ and acetylene $\left(\mathrm{C}_{2} \mathrm{H}_{2}: 10 \mathrm{sccm}\right)$ were used as carrier and source gases for plasma formation. The detailed substrate cleaning process is described elsewhere [16]. The MW CVD chamber was evacuated to a base pressure at approximately $5 \times 10^{-4} \mathrm{~Pa}$ using a turbo pump. The launched microwave power was typically $1000 \mathrm{~W}$ and a constant gas composition pressure is maintained at $15 \mathrm{~Pa}$ and substrate temperature was $550^{\circ} \mathrm{C}$ during deposition. In this work, we used the cover (Figure 3) on the top of the substrate for the quality of graphene synthesis to avoid plasma ultraviolet ray's effect during plasma irradiation. We synthesized graphene with different cover heights (open, $25 \mathrm{~cm}$ and 15 $\mathrm{cm})$ and compared its properties. 


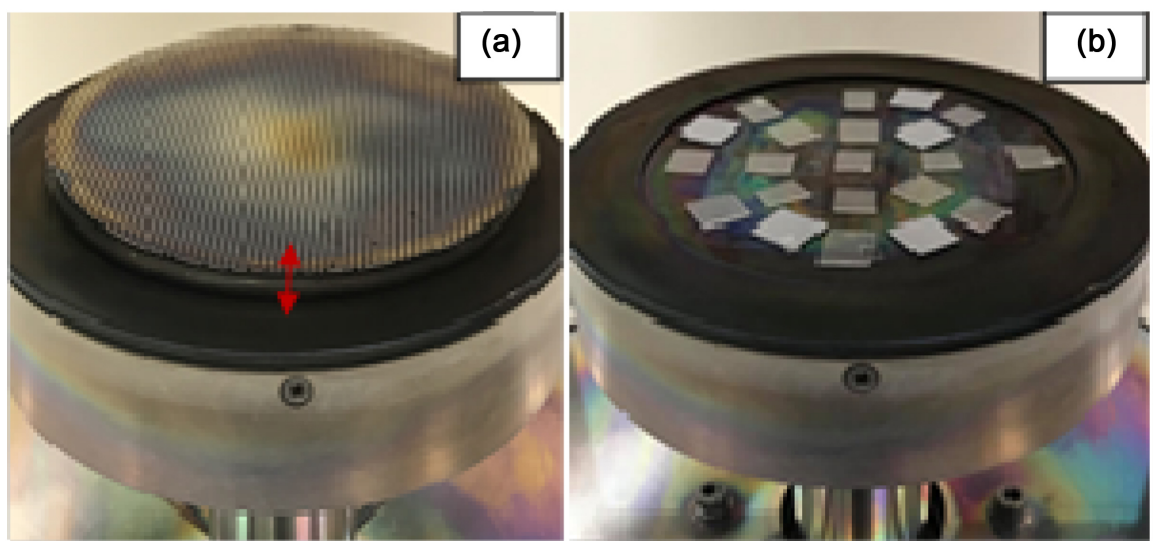

Figure 3. Image pictures of with (a) and without (b) cover during graphene film deposition by microwave plasma CVD.

The graphene films were characterized, by Raman spectroscopy, TEM JEOL JEM-2100F and SEM JEOL JSM-6510LA for structural properties. Four-point probes method for sheet resistance and JASCO V-570 UV/VIS/NIR spectrophotometer for transmittance of the films. The current-voltage characterization of graphene/silicon $(\mathrm{G} / \mathrm{Si})$ Schottky junction solar cell was tasted using JASCO SS-200 W solar simulator in the dark and under AM 1.5 simulated solar radiation.

\section{Results and Discussion}

We believed that the MW-SWP CVD has produced ultraviolet rays during plasma emission. Due to the ultraviolet rays, synthesized graphene films has increased defect density, for making quality of graphene we should have to avoid ultraviolet ray's effect during plasma emission. We made the cover on the substrate so that ultraviolet ray's could not hit directly on the surface substrate (Figure 3). Here we synthesized three types of graphene film with different cover heights (open, $25 \mathrm{~cm}$ and $15 \mathrm{~cm}$ ) during deposition.

Figure 4 shows the Raman spectra (left) of graphene films deposited with different cover heights. Raman spectroscopy is performed at room temperature. Three peaks centered at $1346,1576,2691 \mathrm{~cm}^{-1}$ are assigned to the $\mathrm{D}$ (disorder mode), G (graphite mode) and 2D (D mode overtone) modes of graphene respectively. It is reported that the D-peak represents disordered $\mathrm{sp}^{2}$-hybridized carbon with an amount of $\mathrm{sp}^{3}$-hybrodized carbon, while the G-peaks represent graphite-like $\mathrm{sp}^{2}$-hybridized carbon in the deposited film [17]. The presence of 2D peak shows a good agreement of graphene structure formation into the film. The Raman spectra of carbon material are quite remarkable in order to study the quality of graphene structure [18]. It is believed that the defect of the film is decreased when the film's $I_{d} / I_{g}$ ratio is small. Ratio of the $I_{d} / I_{g}$ is decreasing and FWHM of $2 \mathrm{D}$ peaks is also becoming narrower with decreasing height of the cover. It means that the defect density of graphene has decreased and crystalline structure of the films is improved. It is reported that the FWHM of 2D peak and 

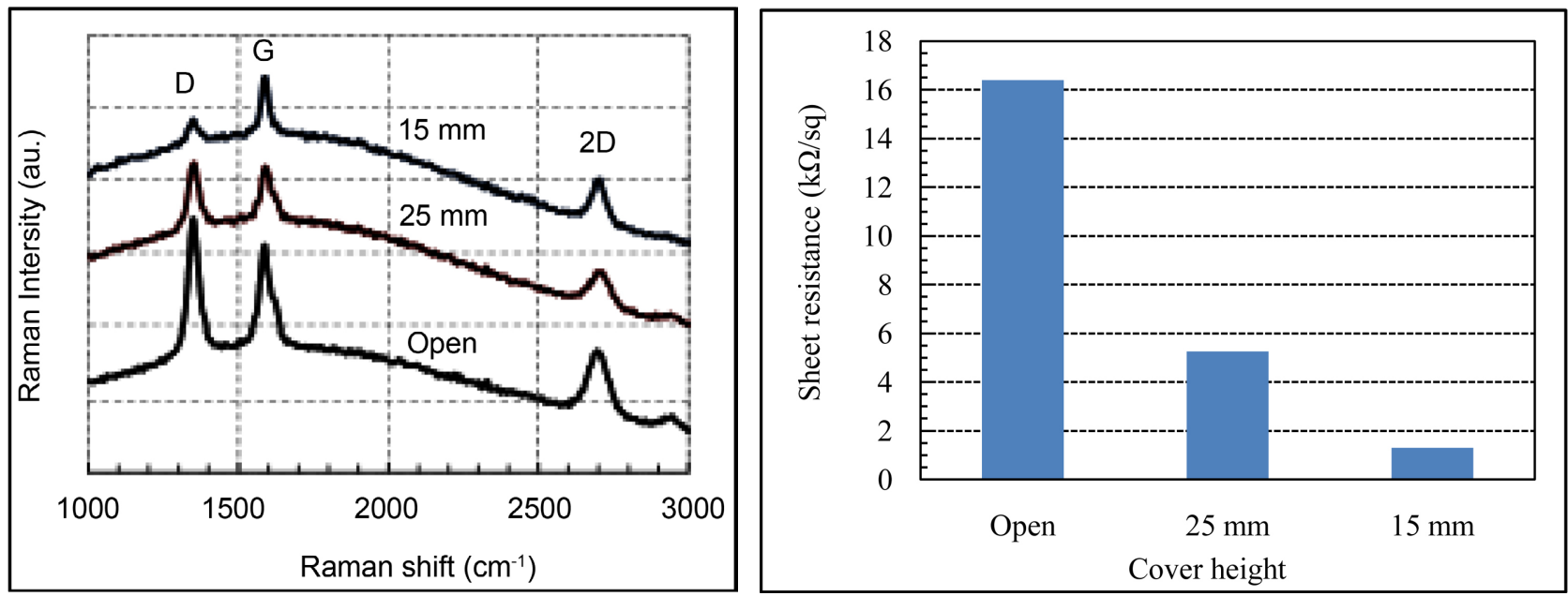

Figure 4. Raman spectra (left) with different cover height and sheet resistance (right) of graphene is decreasing (16.3 to $1.3 \mathrm{k} \Omega / \mathrm{sq}$ ) with cover height (Open to $15 \mathrm{~mm}$ ).

$I_{d} / I_{g}$ of graphene film is decreased means the defect density decreased and quality of the graphene film is improved [19] [20]. It is agreed that the sheet resistance of the graphene films is decreased from $16.3 \mathrm{k} \Omega / \mathrm{sq}$ to $1.3 \mathrm{k} \Omega / \mathrm{sq}$ with decreasing cover height, shown in Figure 4 (right).

Figure 5 shows the SEM image of graphene film deposited on silicon wafer directly with cover height $15 \mathrm{~cm}$ only. It observed that the six-sided, five-sided and other shape polyhedra, which indicate the nucleation of hexagonal and pentagonal carbon rings into carbonaceous nuclei. Moreover, the shape polyhedra are joined each other, indicating the joining behavior of polyhedral shape nanoflakes to form monolayer graphene. We found the same film nature of graphene films with other cover heights.

TEM is used to examine the morphology of the graphene, shown in Figure 6. TEM image reveals the layers and crystalline information of the graphene film synthesized on silicon substrate directly with the cover height of $15 \mathrm{~cm}$. Few layers of graphene ( 3 layers) formation can be observed (b). The intensity pattern (c) of the graphene layers showed that an inter-planar spacing of about $0.38 \mathrm{~nm}$. A fast fourier transform (FFT) image (d) showed a graphite crystalline structure.

The transmittance spectrum of graphene film deposited with cover height 15 $\mathrm{mm}$ is $94.31 \% @ 550 \mathrm{~nm}$ shown in Figure 7. It is reported that transmittance of one-layer graphene is $97.7 \%$, [21] [22] [23]. Our results are qualitatively similar ( $\sim 3$ layers of graphene; Figure 7 , with $94.31 \%$ transmittance) with the results found by other researchers. Comparatively, we got very good quality and high transmittance graphene with cover height $15 \mathrm{~mm}$ than with other height covers. Here we concluded that the ultraviolet rays should avoid during deposition by MW plasma CVD method for the quality of graphene films.

In addition, we fabricated $\mathrm{G} / \mathrm{Si}$ schottky junction solar cells using graphene deposited with a cover height of $15 \mathrm{~mm}$. Figure 8 shows the schematic diagram (a), band diagram (b), current-voltage (I-V) curve (c) and photovoltaic parameters 


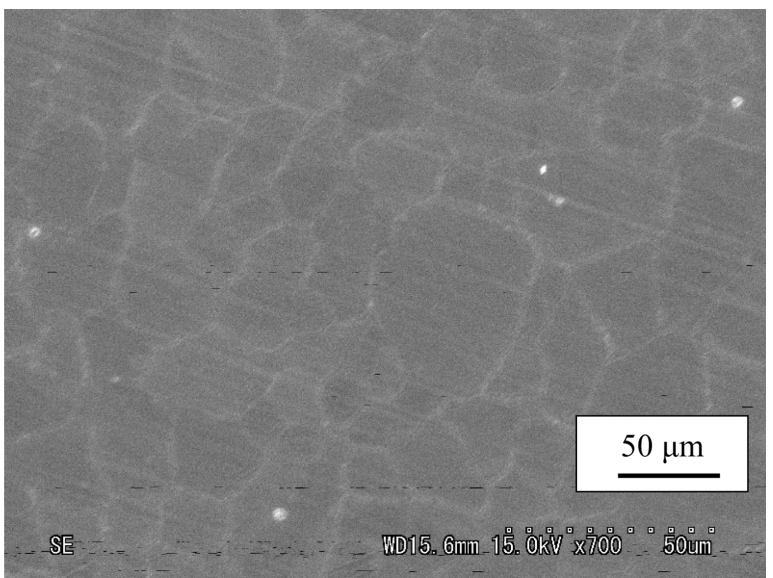

Figure 5. SEM image of graphene film deposited with 15 $\mathrm{mm}$ cover height on silicon wafer directly.
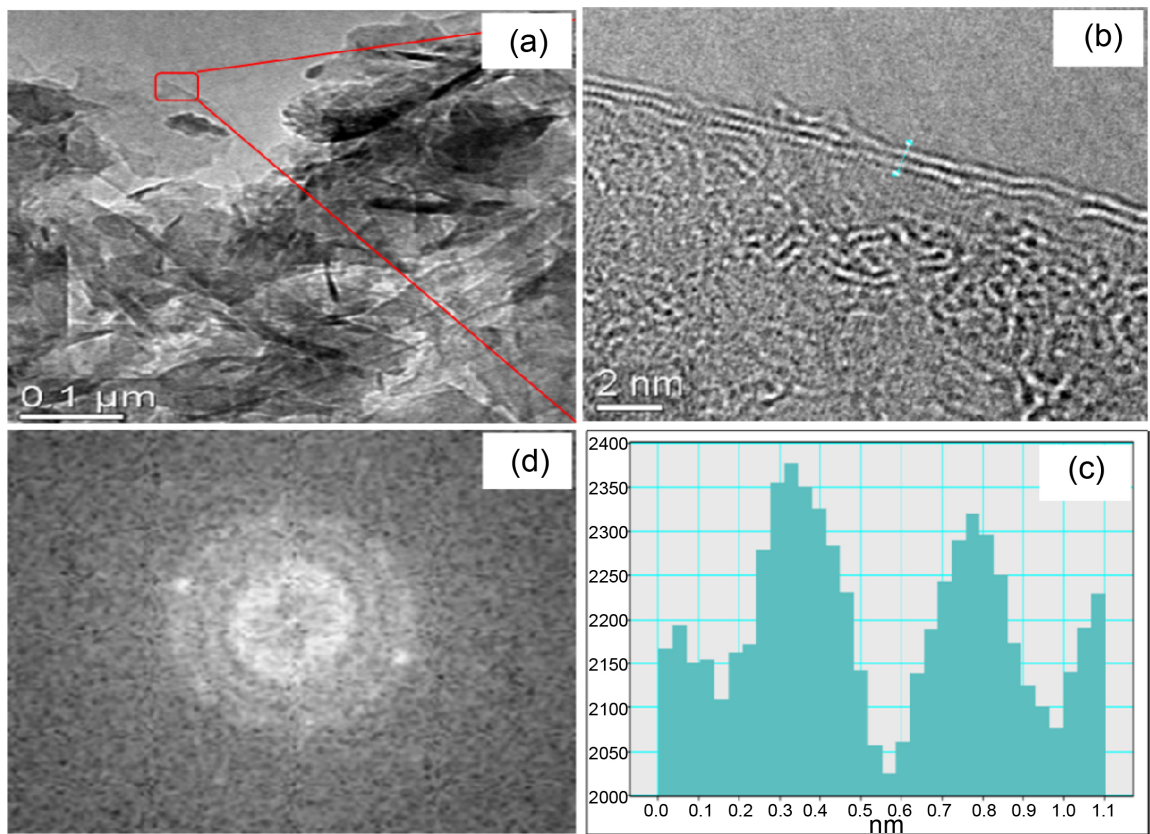

Figure 6. Transmission electron microscopy (TEM) images of the graphene film deposited on silicon substrate directly (15 mm cover height). (a) low resolution; (b) high resolution (HR); (c) intensity pattern; (d) fast fourier transform (FFT).

of G-Si Schottky junction solar cells (d). It showed that photovoltaic behavior with maximum open-circuit voltage $\left(V_{o c}\right) 0.43 \mathrm{~V}$, short circuit current density $\left(J_{s c}\right) 24.01 \mathrm{~mA} / \mathrm{cm}^{2}$, fill factor $(F F) 0.62$ and conversion efficiency $(\eta) 6.39 \%$ are obtained. Compare with conventional Si solar cells, the fabrication process is greatly simplified; just graphene is synthesized directly on n-type crystalline $\mathrm{Si}$ substrate at low temperature $\left(550^{\circ} \mathrm{C}\right)$. G-Si Schottky junction solar cells, the graphene film works on the silicon substrate as a carrier separator (photocarriers) and transport. Moreover, due to high transparency of graphene, most of the incident light is absorbed by silicon, the caused value of short circuit current density is high. 


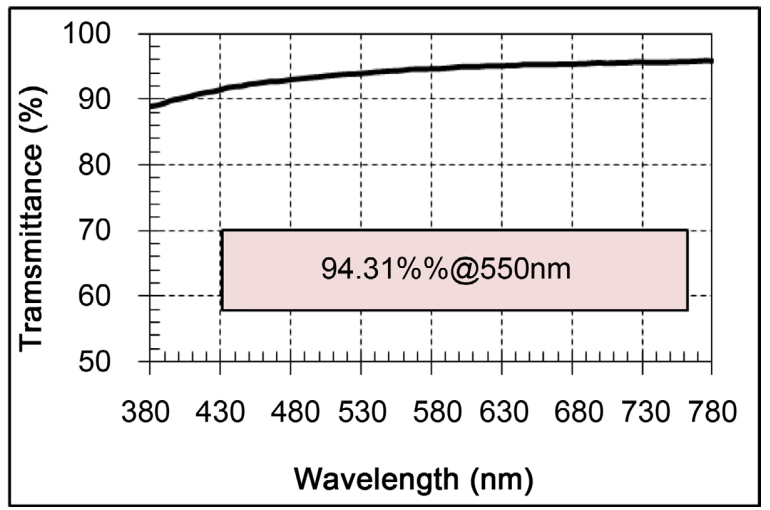

Figure 7. Transmittance spectrum of graphene film deposited with cover height of $15 \mathrm{~mm}$.

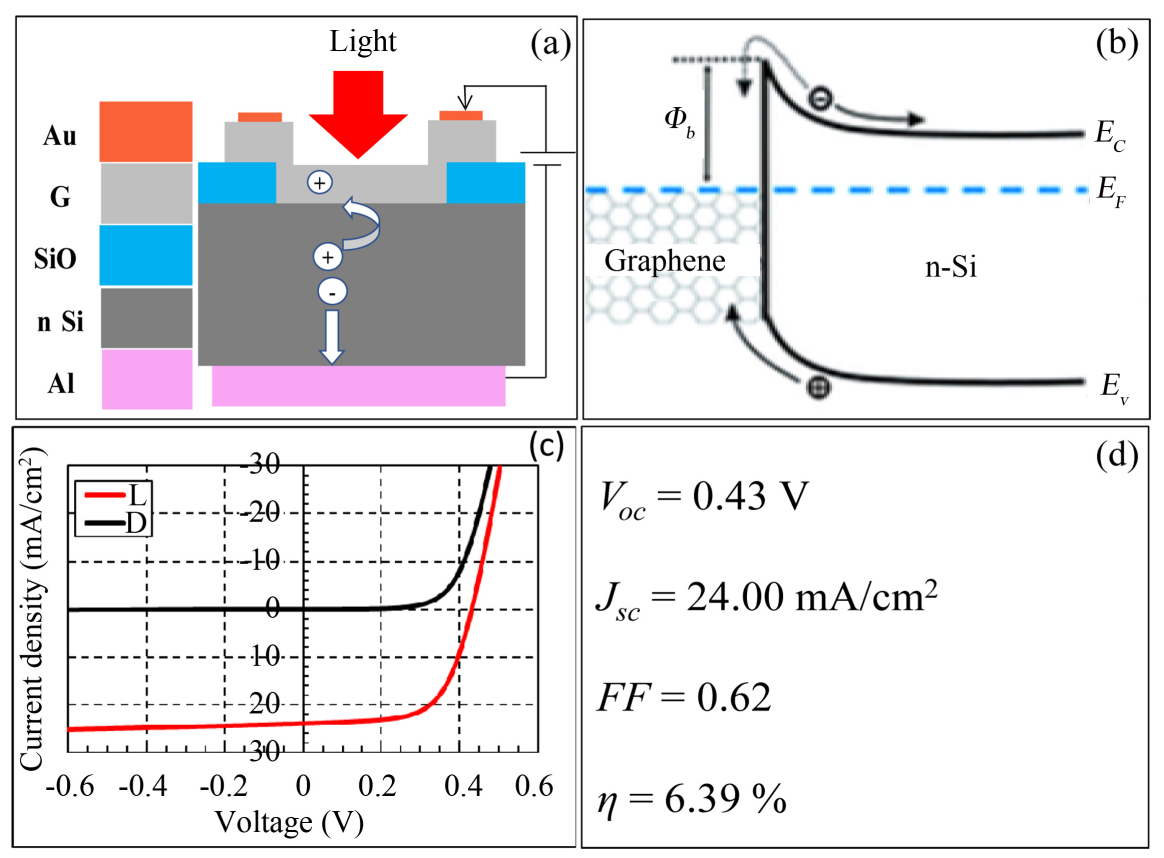

Figure 8. Photovoltaic measurement on the graphene/silicon (G/Si) Schottky junction solar cell: (a) schematic structure diagram; (b) Energy band structure diagram of the G/Si Schottky junction solar cell; (c) I-V characteristic of G/Si Schottky junction solar cell measured in dark and illumination (AM 1.5, $\left.100 \mathrm{~mW} / \mathrm{cm}^{2}\right)$; (d) the photovoltaic parameters.

\section{Conclusion}

Graphene film is deposited directly on silicon substrate by MW-SWP CVD with three different cover heights at $550^{\circ} \mathrm{C}$ for avoiding plasma emission ultraviolet ray's effect, using the hydrocarbon as a source gas. The structural properties of the films were investigated by SEM and TEM measurements. It showed that the formation of a graphene layer on silicon having a crystalline structure with a hexagonal spot in FFT image of graphene was conformed. Raman's result also confirmed that the graphene layers are grown on the silicon substrate. The ratio of $I_{d} / I_{g}$ is decreasing and FWHM of 2D peaks is also becoming narrow with de- 
creasing height of the cover. The sheet resistance decreased $16.3 \mathrm{k} \Omega / \mathrm{sq}$ to 1.3 $\mathrm{k} \Omega / \mathrm{sq}$ with decreasing height of the cover. We fabricated graphene/silicon Schottky junction solar cells and characterized their photovoltaic behavior under dark and light illumination. The open voltage $\left(V_{o c}\right)$ is $0.43 \mathrm{~V}$, short circuit current $\left(J_{s c}\right)$ is $24.01 \mathrm{~mA} / \mathrm{cm}^{2}$, fill factor $(F F)$ is 0.62 and conversation efficiency $(\eta)$ is $6.39 \%$ are obtained.

\section{Acknowledgements}

We would like to express sincere thanks to Mr. Kawamura for his help during TEM measurement.

\section{Conflicts of Interest}

The authors declare no conflicts of interest regarding the publication of this paper.

\section{References}

[1] Novoselov, K.S., Geim, A.K., Morozov, S.V., Jiang, D., Zhang, Y., Dubonos, S.V., Grigorieva, I.V. and Firsov, A.A. (2004) Electric Field Effect in Atomically Thin Carbon Films. Science, 306, 666-669. https://doi.org/10.1126/science.1102896

[2] Geim, A.K. and Novoselov, K.S. (2007) The Rise of Graphene. Nature Materials, 6, 183-191. https://doi.org/10.1038/nmat1849

[3] Katsnelson, M.I. (2007) Graphene: Carbon in Two Dimensions. Materials Today, 10, 20-27. https://doi.org/10.1016/S1369-7021(06)71788-6

[4] Yan, J., Zhang, Y., Goler, S., Kim, P. and Pinczuk, A. (2007) Raman Scattering and Tunable Electron-Phonon Coupling in Single Layer Graphene. Solid State Communications, 143, 39-43. https://doi.org/10.1016/j.ssc.2007.04.022

[5] Lee, C., Wei, X., Kysar, J.W. and Hone, J. (2008) Measurement of the Elastic Properties and Intrinsic Strength of Monolayer Graphene. Science, 321, 385-388. https://doi.org/10.1126/science.1157996

[6] Wang, X., Zhi, L. and Mullen, K. (2008) Transparent, Conductive Graphene Electrodes for Dye-Sensitized Solar Cells. Nano Letters, 8, 323-327. https://doi.org/10.1021/nl072838r

[7] Neto, A.H.C., Guinea, F., Peres, N.M.R., Novoselov, K.S. and Geim, A.K. (2009) The Electronic Properties of Graphene. Reviews of Modern Physics, 81, 109-162. https://doi.org/10.1103/RevModPhys.81.109

[8] Kim, K.S., Zhao, Y., Jang, H., Lee, S.Y., Kim, J.M., Kim, K.S., Ahn, J.H., Kim, P., Choi, J.Y. and Hong, B.H. (2009) Large-Scale Pattern Growth of Graphene Films for Stretchable Transparent Electrodes. Nature, 457, 706-710.

https://doi.org/10.1038/nature07719

[9] Rasuli, R., Iraji Zad, A. and Ahadian, M.M. (2010) Mechanical Properties of Graphene Cantilever from Atomic Microscopy and Density Function Theory. Nanotechnology, 21, Article No. 185503. https://doi.org/10.1088/0957-4484/21/18/185503

[10] Choi, W., Lahiri, I., Seelaboyina, R. and Kang, Y.S. (2010) Synthesis of Graphene and Its Application: A Review. Critical Reviews in Solid State and Materials Sciences, 35, 52-71. https://doi.org/10.1080/10408430903505036 
[11] Wei, D. and Xu, X. (2012) Laser Direct Growth of Graphene on Silicon Substrate. Applied Physics Letters, 100, Article No. 023110. https://doi.org/10.1063/1.3675636

[12] Hong, G., Wu, Q.H., Ren, J. and Lee, S.T. (2012) Mechanism of Non-Metal Catalytic Growth of Graphene on Silicon. Applied Physics Letters, 100, Article No. 231604. https://doi.org/10.1063/1.4726114

[13] Somani, P.R., Somani, S.P. and Umeno, M. (2006) Planer Nano-Graphenes from Camphor by CVD. Chemical Physics Letters, 430, 56-59. https://doi.org/10.1016/j.cplett.2006.06.081

[14] Dato, A., Radmilovic, V., Lee, Z.H., Phillips, J. and Frenklach, M. (2008) Substrate-Free Gas-Phase Synthesis of Graphene Sheets. Nano Letters, 8, 2012-2016. https://doi.org/10.1021/nl8011566

[15] Umeno, M. and Adhikary, S. (2005) Diamond-Like Carbon Thin Films by Microwave Surface-Wave Plasma CVD Aimed for the Application of Photovoltaic Solar Cells. Diamond and Related Materials, 14, 1973-1979.

https://doi.org/10.1016/j.diamond.2005.09.030

[16] Adhikari, S., Omer, A.M.M., Adhikary, S., Rusop, M., Uchida, H. and Umeno, M. (2006) Diamond-Like Carbon Thin Films Grown by Large-Area Surface-Wave Mode Microwave Plasma CVD: Effects of Stage Distance to Microwave Window. Diamond and Related Materials, 15, 913-916. https://doi.org/10.1016/j.diamond.2005.12.012

[17] Dillon, R.O., Woollam, J.A. and Katkanant, V. (1984) Use of Raman Scattering to Investigate Disorder and Crystallite Formation in As-Deposited and Annealed Carbon Films. Physical Review B, 29, 3482-3489.

https://doi.org/10.1103/PhysRevB.29.3482

[18] Ferrari, A.C., Meyer, J.C., Scardaci, V., Casiraghi, C., Lazzeri, M., Mauri, F., Piscanec, S., Jiang, D., Novoselov, K.S., Roth, S. and Geim, A.K. (2006) Raman Spectrum of Graphene and Graphene Layers. Physical Review Letters, 97, Article No. 187401. https://doi.org/10.1103/PhysRevLett.97.187401

[19] Cancado, L.G., Jorio, A., Martins Ferreira, E.H., Stavale, F., Achete, C.A., Capaz, R.B., Moutinho, M.V.O., Lombardo, A., Kulmala, T.S. and Ferrari, A.C. (2011) Quantifying Defects in Graphene via Raman Spectroscopy at Different Excitation Energies. Nano Letters, 11, 3190-3196. https://doi.org/10.1021/nl201432g

[20] Woehrl, N., Ochedowski, O., Gottlieb, S., Shibasaki, K. and Schulz, S. (2014) Plasma-Enhanced Chemical Vapor Deposition of Graphene on Copper Substrates. AIP Advances, 4, Article No. 047128. https://doi.org/10.1063/1.4873157

[21] Bonaccorso, F., Sun, Z., Hasan, T. and Ferrari, A.C. (2010) Graphene Photonics and Optoelectronics. Nature Photonics, 4, 611-622.

https://doi.org/10.1038/nphoton.2010.186

[22] Bao Q. and Loh, K.P. (2012) Graphene Photonics, Plasmonics, and Broadband Optoelectronic Devices. ACS Nano, 6, 3677-3694. https://doi.org/10.1021/nn300989g

[23] Kusmartsev, F.V., Wu, W.M., Yung, K.C. and Pierpoint, M.P. (2015) Application of Graphene within Optoelectronic Devices and Transistors. In: Misra, P., Ed., Applied Spectroscopy and the Science of Nanomaterials. Progress in Optical Science and Photonics, Springer, Singapore, 191-221.

https://doi.org/10.1007/978-981-287-242-5_9 